\title{
Função discursiva em sujeitos nominais marcados supra-segmentalmente
}

\author{
Prof" Dr? Maria Cecília Mollica \\ Universidade Federal do Rio de Janeiro
}

\section{Abstract}

This paper demonstrates empirical evidences for a functional hypothesis about the language prosodic level. Modern Brazilian Portuguese data show that the noun phrases, which have a certain supra-segmental feature, are links in discourse.

Pragmatic motivations are also discussed, specially the interactional point of view. 


\section{HIPOTESE E OBJETIVOS}

$\mathrm{E}$ ste texto ${ }^{1}$ tem 0 objetivo de evidenciar que certa marca supra-segmental incidindo sobre sns sujeitos possui função discursivo-pragmática no português falado na região do Rio de Janeiro. Estudando fenômenos prosódicos de fronteira sintagmática, especialmente entre SN1/SV, apontamos alguns fatores condicionadores à emergência de pausa e/ou de entonação ascendente no referido intervalo sintático (Mollica, 1984 e 1986). Descobrimos que condicionamentos de ordem psicolingüística e discursiva ocorrem para o surgimento desses traços supra-segmentais.

Neste texto, olhamos especialmente para a questão da marca entonacional eventualmente ocorrente sobre os sujeitos. Trabalhamos tão somente com os sujeitos de base nominal, na ordem canônica, porque se apresentaram mais marcados e porque a posposição de sujeito em português não parece equivaler discursivamente à estrutura SV, como alguns trabalhos sobre assunto vêm atestando (Pontes, 1986 e Naro/Votre, 1987). Analisamos dados reais extraídos de fala semi-espontânea, examinando especialmente os sujeitos marcados por uma certa curva entonacional ascendente, que difere das demais, configurando-se como um traço supra-segmental sobre esses sns. Chamamo-la de marca supra-segmental $\mathrm{X}$, reservando aos especialistas sua descrição mais técnica.

A hipótese central consiste em apontar a origem, no discurso, dessas estruturas marcadas, partindo do princípio de que elas cumprem função comunicativa. Teoricamente, nossa suposição encontra respaldo nos postulados de Givón (1979), segundo os quais as estruturas linguiísticas são decorrentes de exigências pragmáticodiscursivas. 


\section{colsão e prosódia}

Todos os sns examinados com marca supra-sègmental $\mathrm{X}$ apresentaram a Função CONECTIVIDADE, assemelhando-se, ao que parece, a algo encontrado para a ordem OV por Braga e Bentivoglio (1987), quando as autoras se referem a diferentes graus de conectividade em dados do espanhol e do português respectivamente. Para nós, a marca $X$ constitui recurso supra-segmental de que a língua lança mão, com a finalidade de estabelecer conexões entre as entidades discursivas. Observe-se o trecho $1:^{2}$

Trecho 1: (falando sobre futebol)

E: “. . E eles me... me puseram ... São Cristóvão, naquela época não era time que você vê hoje não. Era um clube ... era um clube, assim, pequeno mais de time grande. O time/ era muito bem! $O$ clube/ sempre foi um clube pequeno, mas disputava, ... ele disputava realmente campeonato. $O$ São Cristóvão hoje/ faz número e naquela época não, disputava realmente o campeonato."

(MAI4)

Este trecho 1, transcrito de uma parte pequena de entrevista com um falante carioca, ilustra bastante bem a hipótese que estamos lançando. Os sujeitos nominais sublinhados são todos marcados por $X$. Neste exemplo, os referentes desses sns acham-se todos mencionados no próprio discurso, e $\mathrm{X}$ faz-se presente com vistas a conectar um referente a outro.

Tais conexões, no entanto, podem-se dar entre a menção do sintagma sujeito e uma entidade inferível (no sentido de Prince (1979) ), consequientemente ausente do discurso. Veja-se o trecho 2:

Trecho 2: (falando sobre como retirar um talão de cheques num banco)

F: Um talão/ é... é... envolve assim uma... uma pá de... lances, sabe? uma burocraciazinha que deve ser seguida, sabe?

E: Como é o sistema?

F: $\mathbf{E}$ um... sistemazinho que o caixa/ tem poxa, sabe? olhar o lado do rapaz. Ele está aí, sabe? atarefadíssimo, né? Mil coisas na cabeça dele. 
O primeiro sujeito marcado supra-segmentalmente - um talão conecta-se com o tópico geral da conversa 'trabalho num banco'. O sn 'um talão' não fora mencionado anteriormente e está conectado com o tópico geral enquanto entidade inferível, pois constitui um referente claramente disponível no contexto bancário. Conexão semelhante estabelece-se entre o caixa e o contexto banco, no qual está implícito o processo de entrega de um talão de cheques a um cliente. Então, a marca prosódica imprime a correlação entre as entidades, cumprindo a Função Conectividade.

Alguns contextos parecem exigir mais a rede complexa de relações entre referentes num discurso e, conseqüentemente, acabam por favorecer a marca $X$, como vimos em fases anteriores de nossa pesquisa (Mollica, 1984 e 1986). Tomemos inicialmente a enumeração no trecho 3:

\section{Trecha 3: (falando sobre irmãs)}

F: Olha, tenho duas irmãs. O nome da minha irmã mais velha/ se chama... Ana Margarida/ tem dezenove... vinte anos. $\mathbf{E}$ tenho a outra irmã, a me... a... a mais nova que se chama Ana Rosa. Tem dezessete anos. A Margarida/ atualmente está trabalhando em fábrica, na... na... Linhas Correntes, ali em Madureira com a Ana Margarida, $(\ldots \ldots)$

E: E seu pai e sua mãe, como é que é? Seu pai trabalha em quê?

F: Meu Pai/ (hes.) tem lanchonete.

E: Aonde?

F: Na Penha. Minha mãe/ é doméstica. Fica em casa mesmo.

(ANC40)

O trecho 3 é tipicamente enumerativo, caracterizando-se por um tipo de discurso em que as entidades estão distribuídas, geralmente por algum critério comparativo, donde normalmente é muito comum surgir o traço de contrastividade nos sns. Este é o caso dos sujeitos sublinhados no trecho 3 , todos marcados com $\mathrm{X}$ e conectados entre si contrastivamente.

Outro contexto discursivo que pressupõe naturalmente a conexão de elementos, quer nominais, verbais ou adverbiais, é a interação entrevistador/entrevistado. Nele, há quase sempre por 
parte do entrevistador a elicitação de referentes, de eventos ou de circunstâncias. Quando o entrevistador satisfaz à 'provocação', automaticamente um elo estabelece-se entre os interlocutores, dando origem a estruturas que promovam a conexão. A marca X presta-se muito bem ao papel de conector nesse tipo de contexto, como ilustram os sns sublinhados no trecho 4:

\section{Trecho 4:}

E: Nós poderíamos começar por sua profissão, né? Você falou que era mecânico de vôo e falou que não era para consertar avião. O que é mecânico de vôo?

F: Mecânico de vôo/ é uma profissão que foi criada à medida que o avião/ começou a aumentar de tamanho, não é? Então duas pessoas só... porque inicialmente não tinha um piloto...

(MOR45)

$\mathrm{Na}$ interação, o entrevistador 'lança a isca' e o entrevisado 'fisga a isca'. Neste momento, estabelece-se o elo conversacional, e a marca $X$ desempenha a Função de CONECTIVIDADE. Esta configuração discursiva pode acontecer diferentemente, com a conexão realizando-se apenas no final do trecho do falante, como em 5 .

\section{Trecho 5:}

E: Claudir, como é que você sente, por exemplo, o ... o sotaque do carioca? Você acha que o carioca tem sotaque?

F: Ah! Eu acho que o carioca que tem é muita ginga, não é? Muita gíria, né? Como diz assim, é... Ele nã̃o tem assim um sotaque, não tem uma voz carregada. Ele é cheio de gíria. O carioca/ é inovador, e ele está sempre criando linguagem diferente, né?

(CLAU27)

Há casos também em que a elicitação surge naturalmente da própria interação entre os interlocutores, como em 6 .

Trecho 6: (falando da CAPEMI, uma companhia de seguros)

E: Mas fica pesado no salário ou tem um percentual?

F: Tem o percentual. Não, nós temos uma margem consignável, entende? Um percentual para se tirar do salário que recebe. Então, tira... 
E: Uma margem o quê?

F: Consignável

E: Que que é isso?

F: $A$ consignação/ é aquela margem... eles tiram, no caso aqui, é... são trinta por cento do vencimento, entendeu?

(CLAU27)

\section{PROPRIEDADES ESTRUTURAIS DOS SNS MARCADOS POR $X$}

Diante de exemplos como os mostrados aqui, fizemos um levantamento em 5 minutos de cada uma das 17 entrevistas, escolhidas aleatoriamente do conjunto global da amostra 'Censo', 3 e analisamos as propriedades estruturais dos sns marcados com $\mathrm{X}$, com Função de CONECTIVIDADE, somente em contextos interativos. Analisamos os traços \pm tópico, o status do referente no discurso (Prince, 1979), o grau de definição e a quantidade de menção anterior que o referente pudesse ter. Atentos particularmente a esses traços, analisamos 45 casos de sns marcados e conclúmos que: (a) num contexto interacional, sempre que há elicitação do referente por parte do entrevistador satisfeita pelo entrevistado, todas as entidades marcadas são evocadas do ponto de vista discursivo; (b) ser ou não ser mencionado antes mesmo da provocação do entrevistador não é absolutamente relevante. Chegamos, por outro lado, a resultados variáveis para os outros traços, que apresentamos na tabela 1:

TABELA 1

$$
\begin{aligned}
& {[+ \text { tópico }] \ldots \ldots \ldots \ldots \ldots \ldots \ldots \ldots \ldots \ldots \quad \mathbf{3 5 / 4 5} \quad \mathbf{7 7 \%}} \\
& {[\text { - tópico }] \ldots \ldots \ldots \ldots \ldots \ldots \ldots \ldots \ldots \ldots, 10 / 45 \quad 23 \%} \\
& {[+ \text { definido }] \ldots \ldots \ldots \ldots \ldots \ldots \ldots \ldots \ldots 26 / 45 \quad 57 \%} \\
& {[+ \text { genérico }] \ldots \ldots \ldots \ldots \ldots \ldots \ldots \ldots \ldots \ldots, \mathbf{1 4 / 4 5} \mathbf{3 1 \%}} \\
& {[\text { - definido }] \ldots \ldots \ldots \ldots \ldots \ldots \ldots \ldots \ldots, 5 / 45 \quad \mathbf{1 1} \%}
\end{aligned}
$$

Conforme a tabela 1, a maioria dos sns marcados são tópicos, e isso parece bastante previsível, uma vez que o contexto interativo vai supor um sn elicitado que, quase sempre, será o tópico discursivo. Quanto ao grau de definição, os traços [+ definido] e [ + genérico] mostram-se importantes, revelando a forma como as entidades são normalmente elicitadas ao interlocutor. Note-se que 
o [- definido], pouco freqüente, é normalmente entidade nova e, como tal, comumente introduzida no discurso através de outras estruturas. Aqui, esse traço mostrou-se irrelevante para a questão da conectividade.

A importância das estatísticas calculadas para os sns marcados com $X$ reside no fato de as percentagens revelarem tendências estruturais dos sujeitos marcados supra-segmentalmente, entendidas como consequiências fono-morfo-sintáticas do princípio da conectividade. Assim, da necessidade comunicativa, que preconiza correlações discursivas, emerge o recurso lingüístico conectador, preenchendo a função.

\section{COESAO, PROSóda E ESTRUTURA GRAMATIOAL}

E de se salientar o fato de que a marca $X$ não é exclusiva, no português, à Função de Conectividade. Esta pode ser preenchida por outros recursos estruturais, a exemplo da pausa e da estrutura de deslocamento para a esquerda. Em Mollica (1984), já aparece atestada a relevância da pausa em contexto interacional, como em $7: 4$

Trecho 7: (falando da questão de posse de terra)

E: Vem cá, como e que se faz, assim, para pegar esse título de propriedade?

F: O título de propriedade//é você morar no local, ter a sua casa... era incerto. Aí, depois que esse... essa leizinha aí dessas casinhas que está saindo aí, esses apartamentos, aí, a rapaziada começou, né?, pegar o título de propriedade que é para poder ter certeza do que aquele terreno que ele mora é dele...

(ROB15)

Veja-se também um exemplo em que a estrutura de deslocamento para esquerda cumpre a função de que tratamos.

\section{Trecho 8:}

E: Seu pai faz o quê?

F: Meu pai, ele :...meu pai, ele é motorista da Ultragás. 
Observe-se que essas estruturas têm sempre presente a marca $\mathrm{X}$, por isso não nos surpreende o fato de poderem exercer igualmente a Função de Conectividade em contexto interacional.

Nesta análise, constatamos que de fato a marca $X$ suprasegmental sobre sns sujeitos nominais na ordem SV está a serviço da função de conectividade, como exigência de um princípio comunicativo. A comprovação da tese central em vários tipos de contextos está a exigir evidentemente um levantamento mais abrangente $\mathrm{e}$ com maior número de dados. possível imaginar, no entanto, que conexões discursivas podem-se dar também entre eventos e entre circunstâncias, gerando conseqüentemente traços prosódicos, do tipo que analisamos para constituintes nominais, sobre constituintes verbais, adverbiais ou mesmo adjetivais.

Uma discussão teórica sobre os postulados funcionalistas continua a merecer maior cuidado e aprofundamento. Todavia, parece-nos razoável supor que, se as evidências aqui apresentadas não chegam a apontar a direção da seta indicando o tipo de relação entre função comunicativa/estrutura linguística, no mínimo atestam uma correlação estreita entre a marca supra-segmental ' $\mathrm{X}$ ' $\mathrm{e}$ as exigências pragmático-discursivas de conectividade. Trata-se portanto de mais um recurso de coesão (cf. Koch, 1989 e Dijk, 1992), a serviço do texto no sentido mais alargado, projetado no eixo discursivopragmático.

\section{NOTAS}

1

Uma versão preliminar deste texto fol apresentada como comunicação ao VII Congresso Internacional da ALFAL (Asociación de Linglústica y Filologia de América Latína), em San Miguel de Tucumán, em setembro de 1987.

2

O sinal de barra simples (/) simboliza a 'marca $\mathrm{X}$ '.

$\mathbf{3}$

A Amostra 'Censo' constitui um acervo de dados de fala semi-espontanea, contando com 64 entrevistas de uma hora de 64 falantes característicos da região do Rio de Janeiro. A amostra está estratificada em sexo masculino e feminino, em quatro faixas de ldade (de 7 a 14 anos, de 15 a 25 anos, de 26 a 49 anos, de 50 anos em diante), e em três graus de escolarização (da $1^{4}$ à $4^{4}$ série đo $1^{\circ}$ grau, da $1^{4}$ à $3^{4}$ série do $2^{\circ}$ grau). O banco de dados póde ser realizado graças a Convênios firmados entre os órgãos FINEP/INEP/CNPq e UFRJ, no período de 1982 a 1986.

4 o sinal de dupla barra (//) simboliza a pausa. 


\section{REFERENCIAS BIBLIOGRAFICAS}

BRAGA, Maria Luiza; BENTIVOGLIO, Paola. As construçóes OV no espanhol de Caracas e no português do Rio de Janeiro; uma análise comparativa. In: CONGRESSO INTERNACIONAL DA ALFA, 8, 1987. Comunicaçāo... [s.n.t.]

DIJK, Teun T. Van. Cognição, discurso e interação. In: KOCH, Ingedore Villaça (org.). São Paulo: Editora Contexto, 1992). (Coleçấo Caminhos da Lingüística).

GIVON, Talmy. On understanding grammar. New York: Academic Press, 1979.

KOCH, Ingedore Villaça. A coesão textual. São Paulo: Editora Contexto, 1989.

MOLLICA, Maria Cecilia de M. Alguns fatores da pausa entre o sujeito e o verbo. In: Boletim ABRALIM, n 6, 1984.

NARO, Anthony; VOTRE, Sebastião. Emerging sintax as an effect of discourse. [s.l.]: [s.n.], 1987.

PONTES, Eunice. Sujeito: da sintaxe ao discurso. [s.l.] : Editora Atica, 1986. (Ensaios, 125).

PRINCE, Ellen. On the given/new distinction. In: REGIONAL MEETING, 15, 1979. Paper... [s.l.]: CLS, 1979. 